\title{
The Impact of Superior Support on the Behaviors of Technology Innovators Inbiological Agricultural Industry
}

\author{
Xiaocen Yan1, Tiangang Yang2, Binmeizi Zhang1 \\ ${ }^{1}$ School of Government, Beijing Normal University, Beijing, China \\ ${ }^{2}$ College of Chemistry, Beijing Normal University, Beijing, China \\ Email: bnuyanxiaocen@163.com
}

Received 9 May 2016; accepted 6 June 2016; published 9 June 2016

Copyright (C) 2016 by authors and Scientific Research Publishing Inc.

This work is licensed under the Creative Commons Attribution International License (CC BY). http://creativecommons.org/licenses/by/4.0/

(c) ()

\begin{abstract}
The study aims to explore how the superior support affects the behaviors of technology innovatorsin biological agricultural industry. Using 250 samples from biological agricultural industries, a hierarchical regression analysis is developed to examine the relationship. The research results show that the superior support has significant negative correlation with organizational silence and the superior support has significant positive correlation with innovative performance of technology innovators.
\end{abstract}

\section{Keywords}

Superior Support, Organizational Silence, Technology Innovators

\section{Introduction}

Agriculture is the foundation of the national economy, which occupies an important strategic position in the whole national economy. Under the hard constraints of the existing population, resources, and environment, the development of modern agricultural industry has become more and more dependent on scientific and technological innovation, and agriculture has become a more and more high tech industry. Since the advent of transgenic technology in 1983, agricultural biotechnology has developed rapidly, meanwhile, biological seed industry, bio feed, bio pesticides, bio fertilizer technology and industry have also achieved rapid development, which changes the looks of the agricultural industry greatly and depicts a new blueprint for the future development of agriculture. Countries all over the world attach great importance to agricultural science and technology innovation and 
try to improve the quality of agricultural industry and international competitiveness through scientific and technological innovation. Meanwhile, there emerged a number of Multi-National Corporations. Multi-National Corporations in the world have set their strategies which aim at developing the bio agricultural industries vigorously and seize the commanding heights of agricultural biotechnology. In 2014 on the Central Economic Work Conference, the government put forward that it would be a major development trend of China's economic present and future to understand, adapt to and lead the new normal economy. From the perspective of industrial development, biological agricultural industry will develop rapidly further as a strategic emerging industry. Talents and technology are the foundation of the industrial development and the communication among the technology innovative employees and their innovation capacity are the key factors to the development. The overall innovation performance of the corporation depends on the team's innovation performance, while the innovation performance of the team depends on that of the individual employees. Many current studies have shown that improving the employees' innovation performance level is the only way to gain competitive advantages. Innovation performance refers to the new ideas employees intentionally generate, promote and propel in work, groups or organizations in order to help their work, groups or organizations. Innovation performance consists of the generation the promotion and the realization of ideas [1]. Organizational factors are used to be important study objects in early researches. Yang argues that superior support is not only the premise to stimulate innovation but also a valuable perspective to investigate the relationships between organizational situation and employees' innovation performance [2]. Therefore it is significant to investigate the effect of the organizational situation on the innovation behavior of personnel in technological innovation.

However, employees' organizational silence impedes the technology development and employees' innovation in deed. Organizational silence is a kind of collective phenomenon existing in the organization, which refers to the behavior of employees to retain their views on potential problems in organization [3]. Organizational silence brings great harm to not only organizations but also individuals. On the one hand, it will degrade organizational performance and decision quality. On the other, it will decrease employees' satisfaction, bring them anxieties [4] and decrease their enthusiasm and innovation capability [5]. Scholars have investigated the causes of the silence from many perspectives, such as characteristics, leadership features [6], opportunities for communication in the organization [7] and so on. It has been found that actively explore the ways to decrease organizational silence is very critical to create innovative atmospheres among employees. Bowen and Blackmon emphasize that employees tend to express their views when they had a premonition that their own views and opinions put forward can get support from other organization members; otherwise they will chose to be silent. Therefore, only when employees can feel the superior support, will they publicly express their views and decrease organizational silence.

The study hence selected personnel in technological innovation as study object and analyzed interaction of the superior support on innovation behavior and employees' organizational silence thoroughly. It will enrich the academic theories on the one hand, and on the other, promote the improvement of innovation capacity of the personnel in technological innovation and provide significant talent support for the development of the strategic emerging industries.

\section{Literature and Hypothesis}

Scholars have carried out a wide range of research to put forward the concept of superior support. Superior support refers to superior support is the general perception of contribution to the superior and the self degree of concern for employees [8]. Amabile has studied the effects of supportive organizational context on employees and argues that superior support can make employees feel encouraged, respected, and rewarded, therefore, promote their innovation capacity. Superior support includes emotional support, instrumental support for technology or task and social support [9]. Employees innovate initiatively and actively on condition that they feel and accept innovation support, work support and social support. Meanwhile, the scholar finds that superior support influences employees' innovation behavior in three ways: work support, benefit care and value recognition. Compared with employees who feel little superior support, those who feel more support tend to innovate more easily under working pressure [10].

Based on the previous literature discussion, we propose the following hypothesis:

H1: Superior support can promote innovation performance of personnel in technological innovation.

Bowen and Blackmon emphasize that employees tend to express their views when they had a premonition 
that their own views and opinions put forward can get support from other organization members; otherwise they will choose to be silent [11]. Therefore, only when employees feel the superior support, will they publicly express their views and decrease organizational silence. Moreover, abundant superior support can make employees feel responsible to achieve organizational strategies and involve in the development of the organization. Employees will also feel obligated to repay the benefits and opportunities conferred by the organization and offer to help organization [12]. Edmondson found employees will concern more on the problems and dare to suggest if the leaders create an atmosphere which contributes to suggestion such as encourages employees to express their views, motivates suggestion and revolution, enhances employees' sense of security and so on [13]. So we reach the conclusion that sufficient superior support can decrease employees' organizational silence.

Based on the previous literature discussion, we propose the following hypothesis:

H2: Superior support can impede organizational silence in technological innovation.

\section{Method}

\subsection{Sample Source}

Following the principle of random sampling, the study distributed 300 questionnaires to the technological innovation employees in these enterprises, and recycled 280 questionnaires, 250 of which were valid. In 250 valid questionnaires, female $36.7 \%$, male $63.3 \%$, the minimum education qualification was specialist and lower, occupying $25 \%$, Bachelor degree covered $44 \%$ and master degree covered $22 \%$, and the $\mathrm{PhD}$ covering $8.3 \%$. Work experience of the samples ranged from 1 year to 8years and more.

\subsection{Measurement}

(1) Superior support. We adapted the scale developed and used in the studies of Chen et al. [14] in our survey. It adapts Likert five point scale to score and the Cronbach's $\alpha$ coefficient is 0.836 .

(2) Innovation performance. We adapted the innovation behavior scale developed by Janssen [1]. It adapts Likert five point scale to score and the Cronbach's $\alpha$ coefficient is 0.873 .

(3) Organizational silence. We adapted the scale developed by Dyne [15]. It adapts Likert five point scale to score and the Cronbach's $\alpha$ coefficient is 0.841 .

(4) Control Variable. The study selected gender, education and work experience as the control variables. Gender: 1 = female, 2 = male; degree: 1 = specialist and lower, $2=$ undergraduate course, $3=\mathrm{MD}, 4=\mathrm{PhD}$; work experience: 1 = "1year and lower", 2 = "2 - 4 years", 3 = "5 - 8 years"; 4 = "9 years and more”.

\subsection{Common Method Bias}

In this study, the common method bias is tested, which is based on two methods. First, Harman single factor test method is used. The confirmatory factor analysis is used to conduct an exploratory factor analysis of the measurement items of all variables. The common factor number is set as 1 . The results show that this factor explains $27.38 \%$ of variability. A common factor doesn't appear in the unrotated factor structure. Second, the latent error variable control method is used. In the structural equation model, the common method bias is taken as a latent variable. If, in the case of containing method bias as latent variables, the significant fitting of model is better, compared to that case without containing method bias as latent variables, the common method bias effect is verified effectively. The confirmatory factor analysis results show that, the fitting indices of one factor structure model cannot meet the essential goodness of fit, so the common method bias passes the test in this study.

\section{Results and Analysis}

\subsection{Descriptive Statistics and Correlation Analysis}

Table 1 shows the mean value, standard deviation and Pearson correlation coefficient of each variable. The mean value and standard deviation don't have any abnormal phenomena. The correlation results among the variables shows that work experience can impede employees' organizational silence. Superior support has significant negative correlation with organizational silence of the employees $(r=-0.458, p<0.001)$, and significant positive correlation with their innovative performance $(r=0.652, p<0.001)$. 


\subsection{The Effect of the Superior Support on Innovation Behavior and Organizational Silence}

The research applied the regression analysis to measure the effect of superior support on employees' innovation behaviors and organizational silence. As the results shown in Table 2, the variance inflation factor (VIF) of model 1 - 4 are far less than the critical value 10, which suggests the models don't have serious collinearity problem and the results of the analysis for the models are acceptable.

Model 1 and 2 shows the effect of superior support on Innovative performance. In model 2, we introduced superior support into the model after introducing the control variables. The $\beta$ coefficient of the superior support is 0.653 ( $\mathrm{p}<0.001$ ), which means that superior support has an positive effect on innovation behaviors.

Model 3 and 4 shows the effect of superior support on organizational silence. In model 3, we introduced the superior support into the model after introducing control variabls. The $\beta$ coefficient is -0.443 ( $\mathrm{p}<0.001$ ) which means that superior support can impede organizational silence efficiently.

\section{Conclusions and Implications}

This study tested the effect of the superior support on the innovation behaviors and organizational silence of employee. Based on the results, we will do further discussion. The research shows that the organizational silence of the personnel in technological innovation has connections with organizational factors. Organizational silence is a potential harm on the organization and is considered a stumbling block affecting the decision quality. Employees choose a "safe" way to respond-keeping silent for various reasons, such as for fear of retaliation from leaders or co-workers' ridicule. Sufficient superior support will enhance employees’ sense of security, make em-

Table 1. Mean value, standard deviation and correlation coefficient of the variables.

\begin{tabular}{|c|c|c|c|c|c|c|c|}
\hline & Mean & Standard Deviation & 1 & 2 & 3 & 4 & 5 \\
\hline 1. Gender & 1.63 & 0.483 & & & & & \\
\hline 2. Degree & 2.14 & 0.889 & $-0.129^{*}$ & & & & \\
\hline 3. Years of Working & 2.11 & 0.978 & -0.053 & $0.274^{* *}$ & & & \\
\hline 4. Superior Support & 2.17 & 0.856 & -0.097 & 0.109 & 0.092 & & \\
\hline 5. Innovative Performance & 2.25 & 0.907 & 0.001 & $0.127^{*}$ & 0.055 & $0.652^{* * *}$ & \\
\hline 6. Organizational Silence & 2.35 & 0.590 & 0.013 & $-0.170^{* *}$ & $-0.144^{*}$ & $-0.458^{* * *}$ & $-0.379^{* * *}$ \\
\hline
\end{tabular}

Table 2. Analysis of the influence of superior support on the technology innovative employees' innovative performance and organizational silence.

\begin{tabular}{|c|c|c|c|c|}
\hline & \multicolumn{2}{|c|}{ Innovative performance } & \multicolumn{2}{|c|}{ Organizational silence } \\
\hline & M1 & M 2 & M3 & M4 \\
\hline Constant & 1.878 & 0.407 & 2.704 & 3.354 \\
\hline Gender & 0.018 & 0.072 & -0.011 & -0.047 \\
\hline Degree & $0.123^{*}$ & 0.071 & $-0.142^{*}$ & -0.107 \\
\hline Work Experience & 0.022 & -0.021 & -0.105 & -0.076 \\
\hline Superior Support & & $0.653^{* * *}$ & & $-0.443^{* * *}$ \\
\hline $\mathrm{R}^{2}$ & 0.017 & 0.433 & 0.039 & 0.231 \\
\hline Adjusted $\mathrm{R}^{2}$ & 0.007 & 0.426 & 0.029 & 0.221 \\
\hline $\mathrm{F}$ & 1.701 & 56.464 & 4.013 & 73.755 \\
\hline
\end{tabular}

Notes: ${ }^{*}$. Correlation is significant at the 0.05 level (2-tailed); ${ }^{* *}$. Correlation is significant at the 0.01 level (2-tailed); ${ }^{* * *}$. Correlation is significant at the 0.001 level (2-tailed). 
ployees more willing to offer suggestions to the organization actively. Meanwhile, enough perception of superior support will make employee more loyal to the organization, think about organizational development, keep enthusiastic at work, less likely retain the view and express their views and provide information more positively.

Therefore, superior support is the key to inspire personnel in technological innovation in enterprises' management practice. Given the features of personnel in technological innovation, organizations should encourage employees to think innovatively, allow them study and grow through trying and making mistakes and provide them with adequate resource support. Managers should give the personnel appropriate free space to work freely, respect different opinions, give positive feedbacks, and appropriately empower them and support their innovative ideas. Moreover, it creates a supportive cultural atmosphere strongly, encourages support and assistance among employees, helps employees exchange innovative experiences and lessons through seminars or conferences, decreases personnel's organizational silence constructively, and creates a platform to improve innovation behavior. Furthermore, enterprises should often organize altruistic group activities to increase the love and mutual assistance among employees. Organizations can stimulate employees' sense of superior support and decrease employees’ organizational silence, and therefore stimulate their Innovative performance.

\section{References}

[1] Janssen, O. (2000) Job Demands, Perceptions of Effort-Reward Fairness and Innovative Work Behavior. Journal of Occupational and Organizational Psychology, 73, 287-302. http://dx.doi.org/10.1348/096317900167038

[2] Yang, Y. (2014) A Study on the Influence Mechanism of Matching between People and Organizations on the Innovation Behavior of Employees. China Water Power Press, 50-51.

[3] Morrison, E.W. and Milliken, F.J. (2000) Organizational Silence: A Barrier to Change and Development in a Pluralistic World. Academy of Management Review, 25, 706-725.

[4] Ma, X.Y. (2009) Research on the Relationship between Organizational Silence and Employee Satisfaction in HighTech Enterprises. Southwestern University of Finance and Economics, 5, 16-17.

[5] Wang, Z.Z. (2014) Employee Silence: Innovation Barrier and Solutions for Intellectual Organizations. Journal of Guangdong Polytechnic Normal University, 5, 65-71.

[6] Zhang, J.P. (2013) The Influence of Private Enterprise Leadership Style on Employee Silence. Management Observation, 9,128-131.

[7] Zhao, C.L. (2010) Study on Status of Organizational Silence and Countermeasures under the Chinese Background. Chongqing University, Chongqing, 10-11.

[8] Kottke, J.L. and Sharafinski, C.E. (1988) Measuring Perceived Supervisory and Organization Support. Education and Psychological Measurement, 48, 1075-1079. http://dx.doi.org/10.1177/0013164488484024

[9] Amabile, T.M., Conti, R., Coon, H., Lazenby, J. and Herron, M. (1996) Assessing the Work Environment for Creativity. The Academy of Management Journal, 39, 1154-1184. http://dx.doi.org/10.2307/256995

[10] Chen, H. (2011) Research on the Relationship between Job Demand and Innovative Work Behavior. Technoeconomics \& Management Research, 1, 41-45.

[11] Bowen, F. and Blackmon, K. (2003) Spirals of Silence: The Dynamic Effects of Diversity on Organizational Voice. Journal of Management Studies, 40, 1393-1417. http://dx.doi.org/10.1111/1467-6486.00385

[12] Li, R. and Ling, W.Q. (2010) Influence of Supervisor's Support on Employee's Work Attitude and Silence. Behavior. Journal of Business Economics, 5, 31-39.

[13] Edmondson, A.C. (2003) Speaking up in the Operating Room: How Team Leaders Promote in Interdisciplinary Action Teams. Journal of Management Studies, 6, 1419-1452. http://dx.doi.org/10.1111/1467-6486.00386

[14] Chen, X.J., Zhang, Q. and Chen, G. (2011) The Mediating Effect of Perceived Supervisor Support on the Relationship between Psychological Contract Violation and Organizational Citizenship Behavior. Chinese Journal of Ergonomics, 17, 19-23.

[15] Ferris, G.R. and Kacmar, K.M. (1992) Perceptions of Organizational Politics. Journal of Management, 18, 93-116. http://dx.doi.org/10.1177/014920639201800107 